\title{
Non-invasive ventilation in acute respiratory failure: a meta-analysis
}

\author{
Authors: Yu-Jing Liu, ${ }^{A}$ Jing Zhao ${ }^{B}$ and Hui Tang ${ }^{C}$
}

Non-invasive positive-pressure ventilation (NPPV) has assumed an important role in the management of respiratory failure because it provides ventilatory support without the need for an invasive airway. However, its effectiveness remains unclear. We performed this meta-analysis to investigate the utility of NPPV intervention in patients with acute respiratory failure (ARF). A comprehensive literature search identified 12 studies enrolling a total of 963 patients from Medline, PubMed, Cochrane and EMBASE databases that assessed the effectiveness of NPPV versus conventional mechanical ventilation and/or non-ventilation therapy in patients with ARF, irrespective of the underlying aetiology, as well as mortality rate and the length of intensive care unit (ICU) or hospital stay. The usage of NPPV was associated with significantly decreased intubation (pooled $O R=0.23$, 95\% CI $0.12-0.42, p<0.001$ ) and ICU mortality rate (pooled $\mathrm{OR}=0.34,95 \% \mathrm{CI} 0.20-0.60, \mathrm{p}<0.001$ ), but did not influence the hospital mortality rate (pooled $\mathrm{OR}=0.77,95 \%$ CI $0.32-1.81$, $\mathrm{p}=0.543$ ) and the length of ICU or hospital stay (ICU stay: difference in means $=0.38,95 \% \mathrm{CI}-3.01$ to $3.77, \mathrm{p}=0.825$; hospital stay: difference in means $=2.76,95 \% \mathrm{CI}-1.74$ to 7.27 , $p=0.229$ ). In conclusion, usage of NPPV in patients with ARF is associated with lower intubation and in-ICU mortality rate.

KEYWORDS: acute respiratory failure, positive-pressure respiration, noninvasive

\section{Introduction}

Respiratory failure is a syndrome in which the respiratory system fails in one or both of its gas exchange functions. Acute respiratory failure (ARF) is characterised by life-threatening derangements in arterial blood gases and acid-base status that develops over hours or days. ARF does not require immediate intubation but is potentially life threatening. ${ }^{1}$ A number of underlying pathophysiologic processes, such as chronic obstructive pulmonary disease (COPD), acute

Authors: A director, Department of Medical Engineering, Army General Hospital, Beijing, China; ${ }^{\text {B }}$ director, Department of Thoracic Surgery, Army General Hospital, Beijing, China; ' senior technician, Department of Medical Engineering, Army General Hospital, Beijing, China cardiogenic pulmonary oedema (ACPE), pneumonia, acute lung injury/acute respiratory distress syndrome (ALI/ARDS), asthma, obesity hypoventilation syndrome, interstitial lung disease and respiratory failure postoperatively and posttransplantation, can lead to ARF. ${ }^{2}$

Treatment of patients who develop ARF often requires mechanical ventilatory assistance. ${ }^{3}$ Traditionally, it is done by the endotracheal intubation and subsequent application of positive-pressure ventilation. ${ }^{4}$ However, endotracheal intubation can lead to a number of complications, including barotraumas, upper-airway trauma and pneumonia. ${ }^{3,4} \mathrm{NPPV}$ was developed in an attempt to avoid the morbidity associated with endotracheal intubation and has become one of the most significant recent advances in respiratory medicine. ${ }^{5}$ Non-invasive positive-pressure ventilation (NPPV) is a more comfortable and convenient type of ventilation and is increasingly being used by emergency medical services for treatment of patients in respiratory distress. ${ }^{6}$

It is recognised that patients with hypercapnic respiratory failure secondary to COPD are the ones to benefit the most from NPPV. ${ }^{7,8}$ The application of NPPV in hypoxaemic ARF has also been researched over the last two decades. Despite the effort, the data regarding the use of NPPV in patients with ARDS are limited and controversial. Two meta-analyses of randomised controlled trials (RCTs) did not support the use of NPPV in hypoxaemic ARF and ALI/ ARDS. ${ }^{2,9}$ It was reported that the presence of ARDS was one of the factors independently associated with NPPV failure, and the highest intubation rate occurred among patients with ARDS after NPPV. ${ }^{10-12}$ In an observational cohort study ${ }^{13}$ and a prospective, multicentre cohort study, ${ }^{11}$ approximately half of patients with ARDS had NPPV failures. Additionally, in a multicentre RCT, early NPPV compared with oxygen therapy alone did not reduce 28 -day mortality in immunocompromised patients admitted to the ICU with hypoxemic acute respiratory failure. ${ }^{14}$ In other studies, however, it was shown that the use of NPPV eliminated the need for endotracheal intubation in $50-86 \%$ of ARDS patients. ${ }^{12,15,16}$ When the use of NPPV was evaluated in specific cases of hypoxaemic ARF (eg following lung resection surgery or pneumonia in immunocompromised individuals) it was shown to reduce mortality and endotracheal intubation rates. ${ }^{17}$ Additionally, NPPV has been shown to be effective when used as an initial mode of assisted ventilation in a small study by Rocker et al. ${ }^{18}$ 
The controversial results of the previous studies regarding the potential benefits of NPPV may be explained by the variable degree of hypoxia, the presence of comorbidities and complications, and illness severity. ${ }^{5}$ In order to further assess and summarise the efficacy of NPPV for patients with ARF of various aetiologies, we performed a meta-analysis. The aim of our study was to determine whether NPPV compared with conventional mechanical ventilation and/or non-ventilation therapy affects the rate of endotracheal intubation, length of ICU and hospital stay, and ICU and overall mortality in patients with ARF.

\section{Methods}

\section{Search strategy}

We followed the PRISMA guidance for systematic reviews of observational and diagnostic studies. ${ }^{19}$ We searched the published literature using Medline, PubMed, Cochrane and EMBASE databases with various combinations of the following keywords: 'noninvasive ventilation' AND 'acute lung injury' OR 'acute respiratory distress syndrome' OR 'Acute respiratory failure'; 'noninvasive ventilation' AND 'acute lung injury' OR 'acute respiratory distress syndrome'. References in relevant primary publications were hand-searched to identify other eligible trials. The described searches included original literature published up to 10 June 2015.

For this meta-analysis, we included papers that assessed the effectiveness of NPPV interventions versus conventional mechanical ventilation and/or non-ventilation therapy in patients with ARF, irrespective of the underlying aetiology, in RCTs, two-arm prospective studies and retrospective studies. Additionally, we included studies that examined the association of NPPV with the mortality rate and the length of stay in the ICU or in the hospital. We excluded letters, comments, editorials, case reports, proceedings, personal communications and cohort studies, as well as studies that did not have quantitative outcomes. Additionally, we excluded studies that analysed patients who chronically used NPPV at home, had a tracheostomy or recent oesophageal surgery, received NPPV as a palliative treatment, suffered malignant arrhythmia, chronic kidney diseases or fluid overload, and those with hemodynamic instability.

\section{Data extraction}

Data were extracted independently by two reviewers. A third reviewer was consulted in the case of disagreements. We extracted data on study population (number, age and gender of subjects in each group), study design and the major outcomes.

\section{Quality assessment}

We assessed the quality of RCTs using the Cochrane Collaboration's Tool. ${ }^{20}$ Briefly, the risk of bias was assessed via seven different criteria: selection bias (random sequence generation and allocation concealment), performance bias (blinding of participants and personnel), detection bias (blinding of outcome assessment), attrition bias (incomplete outcome), reporting bias (selective outcome reporting) and inclusion of intention-to-treat analysis. For non-RCTs, ACROBAT-NRSI (A Cochrane Risk Of Bias Assessment Tool: for Non-Randomized Studies of Interventions) was used. ${ }^{21}$ It includes domains covering bias due to confounding, bias in the selection of participants into the study, bias due to departures from intended interventions, bias due to missing data, bias in taking measurements and bias in the selection of the reported result. Quality assessment was performed by two independent reviewers, and a third reviewer was consulted if no consensus could be reached.

\section{Statistical analysis}

The number of events was extracted for dichotomous outcome variables (intubation rate and mortality), and mean and standard deviation were extracted for continuous outcomes (length of ICU/hospital stay). Odds ratios (OR) with 95\% confidence intervals (CI) were calculated for dichotomous outcome variables between patients in the NPPV group and control group for all of the studies combined. An OR of less than 1 indicated that the NPPV group was favoured. For continuous outcomes, the differences in means with $95 \% \mathrm{CI}$ between two groups were calculated. If the difference in means was less than 0, the NPPV was favoured.

\section{Heterogeneity assessment}

We performed a $\chi$ 2-based homogeneity test and determined the Q statistics and the inconsistency index $\left(\mathrm{I}^{2}\right)$. The Q statistic was defined as the weighted sum of the squared deviations of the estimates of all studies; $\mathrm{p}<0.10$ was considered statistically significant for heterogeneity. Because the tests for heterogeneity are often underpowered ${ }^{22}$ and per recommendations of the National Research Council report, ${ }^{23}$ we used random-effects models in our analysis. Sensitivity analysis was carried out using the leave one-out approach. Publication bias was assessed by running Egger's test and constructing a funnel plot. Subgroup analyses were performed according to study design and level of $\mathrm{PaO}_{2} / \mathrm{FiO}_{2}$ at randomisation. All analyses were performed using Comprehensive Meta-Analysis Software, version 2.0 (Biostat, Englewood, NJ, USA).

\section{Results}

\section{Basic characteristics of included studies}

Using the keyword-based search, we initially identified 347 articles. Exclusion of irrelevant articles left 48 studies for full text reviewing. Of these, seven were single-arm studies, eight analysed different intervention groups, two were review articles, two were duplicate articles, 15 failed to provide an outcome of interest and two articles were published in a language other than English.

Thus, we were able to identify 12 eligible publications. ${ }^{16,24-34}$ The flow chart describing selection of the trials for the analysis is presented in Fig 1.

Ten of the studies were RCTs and two were prospective studies. The 12 studies recruited a total of 963 patients: 295 in the NPPV group and 665 in the control group. The characteristics of the studies are summarised in Table 1. The age of patients ranged from 16 to 76 years. The proportion of patients that were male ranged from $17-82 \%$ in the NPPV group and $46-61 \%$ in the control group.

\section{Outcomes and heterogeneity}

A total of 11 studies provided rates of intubation and were included in the meta-analysis. Because tests for heterogeneity 


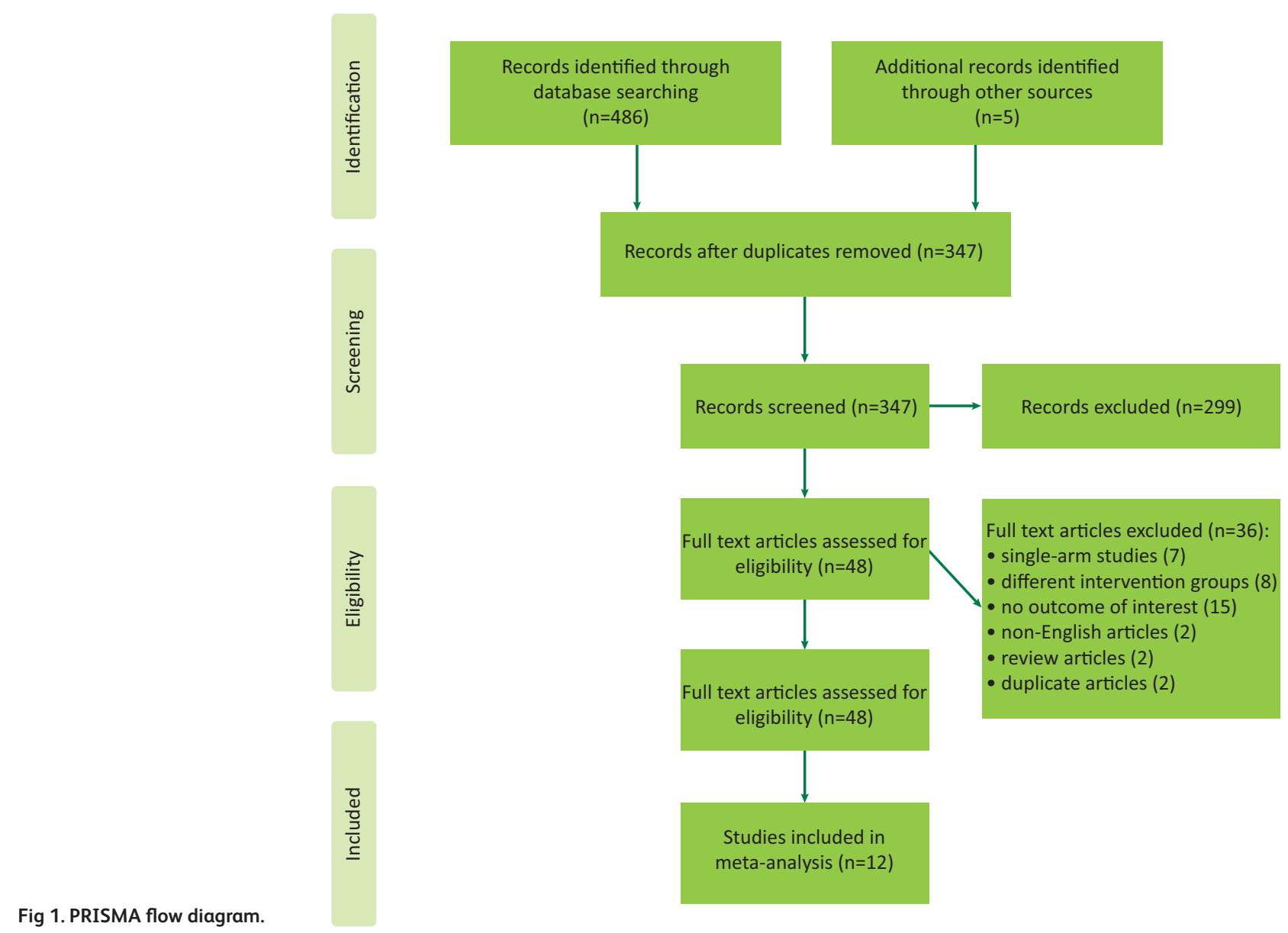

are often underpowered, ${ }^{22}$ random-effects models were used for each outcome. There was significant heterogeneity among the 11 studies (heterogeneity test: $\mathrm{Q}=20.137, \mathrm{I}^{2}=50.34 \%, \mathrm{p}=0.028$ ). The overall analysis revealed that the rate of intubation was significantly lower in the NPPV group (pooled OR=0.23, 95\% CI $0.12-0.42, \mathrm{p}=0.001$, Fig 2). The RCTs reported similar results (pooled $\mathrm{OR}=0.22,95 \%$ CI $0.11-0.42, \mathrm{p}<0.001$ ). Only one non-RCT ${ }^{25}$ provided rates of intubation, therefore subgroup analysis for non-RCTs was not performed.

A total of five RCTs ${ }^{16,24,30,32,33}$ provided ICU mortality rate and were included in the meta-analysis. There was no significant heterogeneity among the five studies (heterogeneity test: $\mathrm{Q}=1.176, \mathrm{I}^{2}=0 \%, \mathrm{p}=0.882$ ). The overall analysis revealed that in-ICU death was significantly less frequent in the NPPV group compared with the conventional therapy group (pooled $\mathrm{OR}=0.34,95 \%$ CI $0.20-0.60, \mathrm{p}<0.001$, Fig $3 \mathrm{~A}$ ).

A total of seven studies ${ }^{16,25-27,29,32,34}$ provided in-hospital mortality and were included in the meta-analysis. There was significant heterogeneity among seven of these studies (heterogeneity test: $\mathrm{Q}=13.145, \mathrm{I}^{2}=54.36 \%, \mathrm{p}=0.041$ ). The overall analysis revealed that there was no significant difference in the in-hospital mortality for the NPPV interventions versus conventional therapy group (pooled $\mathrm{OR}=0.89,95 \% \mathrm{CI}$ $0.42-1.89, \mathrm{p}=0.754$, Fig 3B). The results were similar for both RCTs (pooled OR=0.56, 95\% CI 0.20-1.54, $\mathrm{p}=0.260$ ) and non-RCTs (pooled OR=1.57, 95\% CI 0.51-4.87, $\mathrm{p}=0.433$ ). There was significant heterogeneity in the length of ICU or hospital stay among the studies (Fig 4). The overall analysis revealed that there was no significant difference between the NPPV and conventional therapy groups for the length of ICU or hospital stay (ICU stay: difference in means $=-1.39,95 \% \mathrm{CI}-3.54$ to $0.76, p=0.204$, Fig 4A; hospital stay: difference in means $=0.16$, $95 \%$ CI -1.05 to $1.37, p=0.792$, Fig $4 B$ ). However, a non-RCT study ${ }^{26}$ reported that patients in the NPPV group had longer hospital stays than those in the conventional therapy group (difference in means $=12.70,95 \%$ CI $8.51-16.89, \mathrm{p}<0.001$ )

\section{Sensitivity analysis and publication bias}

Sensitivity analyses were performed using the leave-one-out approach (S1 - Table S1). The direction and magnitude of combined estimates did not vary markedly with the removal of the studies, indicating that the meta-analysis had good reliability and the data was not overly influenced by each study.

There was no significant evidence of publication bias for the rate of intubation and the length of ICU stay (S2 - Fig S1) as assessed by the use of Egger's test ( $p=0.329$ for rate of intubation; $\mathrm{p}=0.098$ for length of ICU stay). In addition, for in-ICU or in-hospital mortality and the length of hospital stay, the power of the test for publication bias were too low to distinguish chance from real asymmetry because of the small number of studies. 

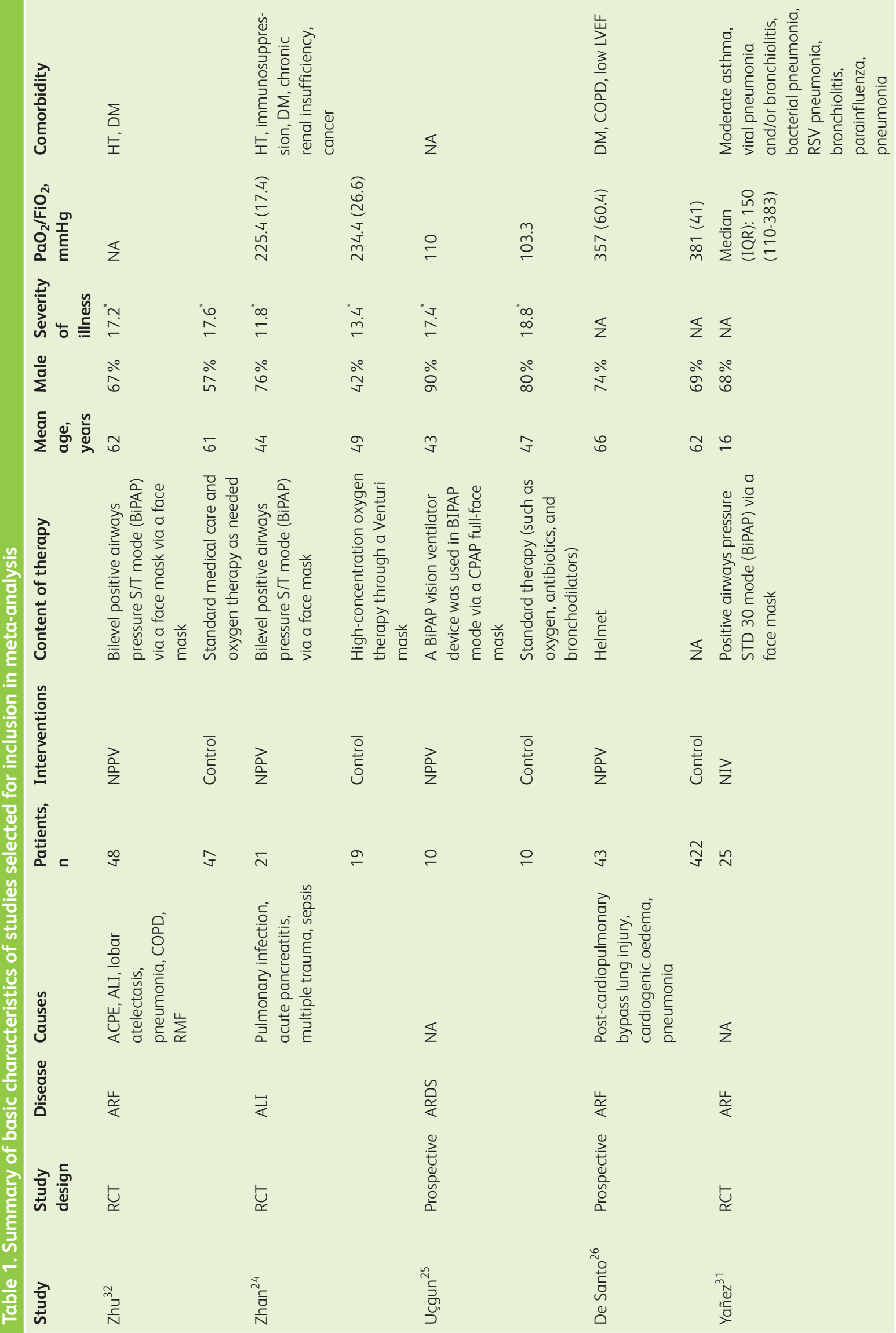

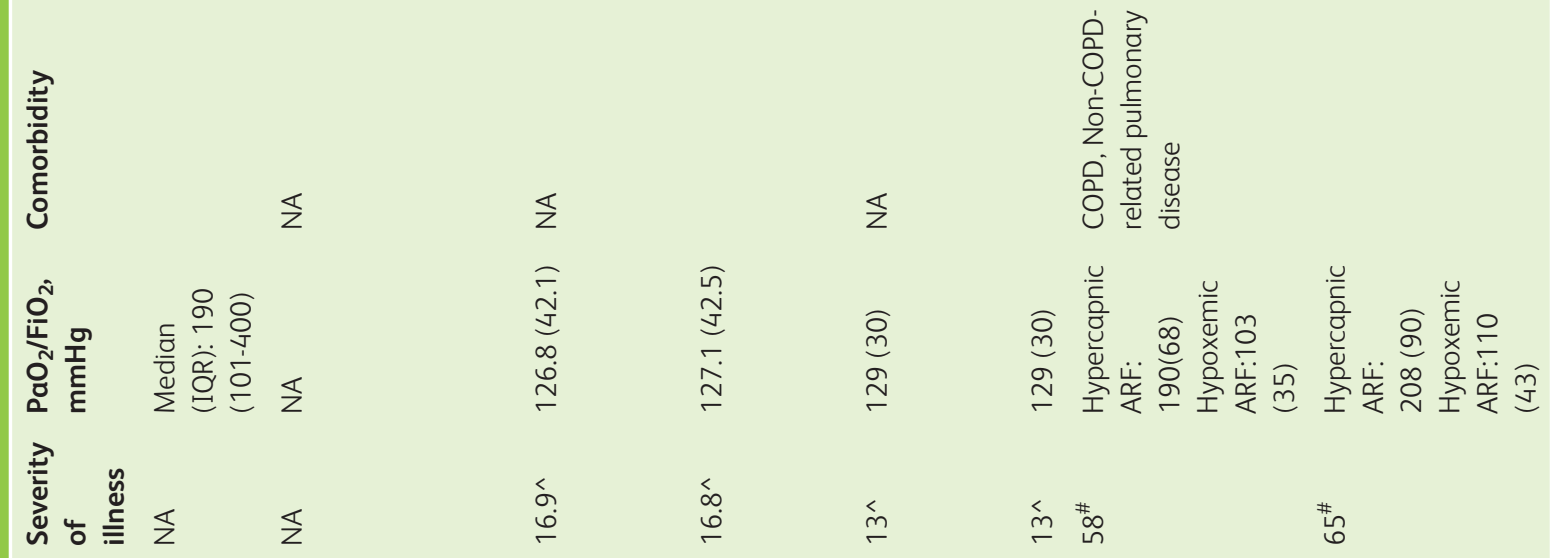

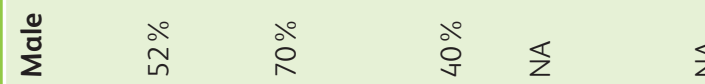

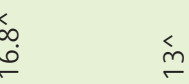

$\stackrel{i}{m} \quad \stackrel{i}{*}$

范

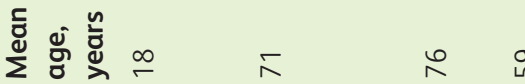

ชำ

भู ป ำ

$\stackrel{\infty}{i n}$

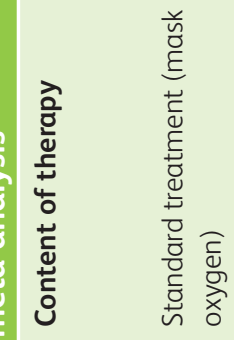
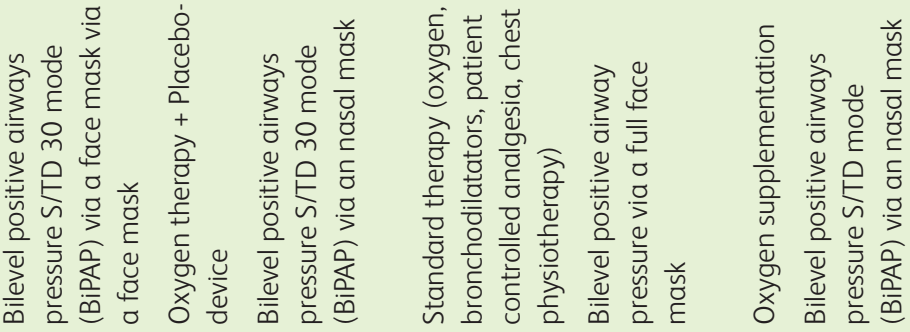

高

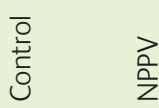

흘

흔

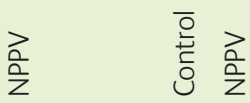

은

s

竞= 岀

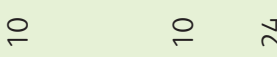

$\stackrel{\sim}{2}$

ㅇ

ㅇ

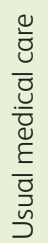
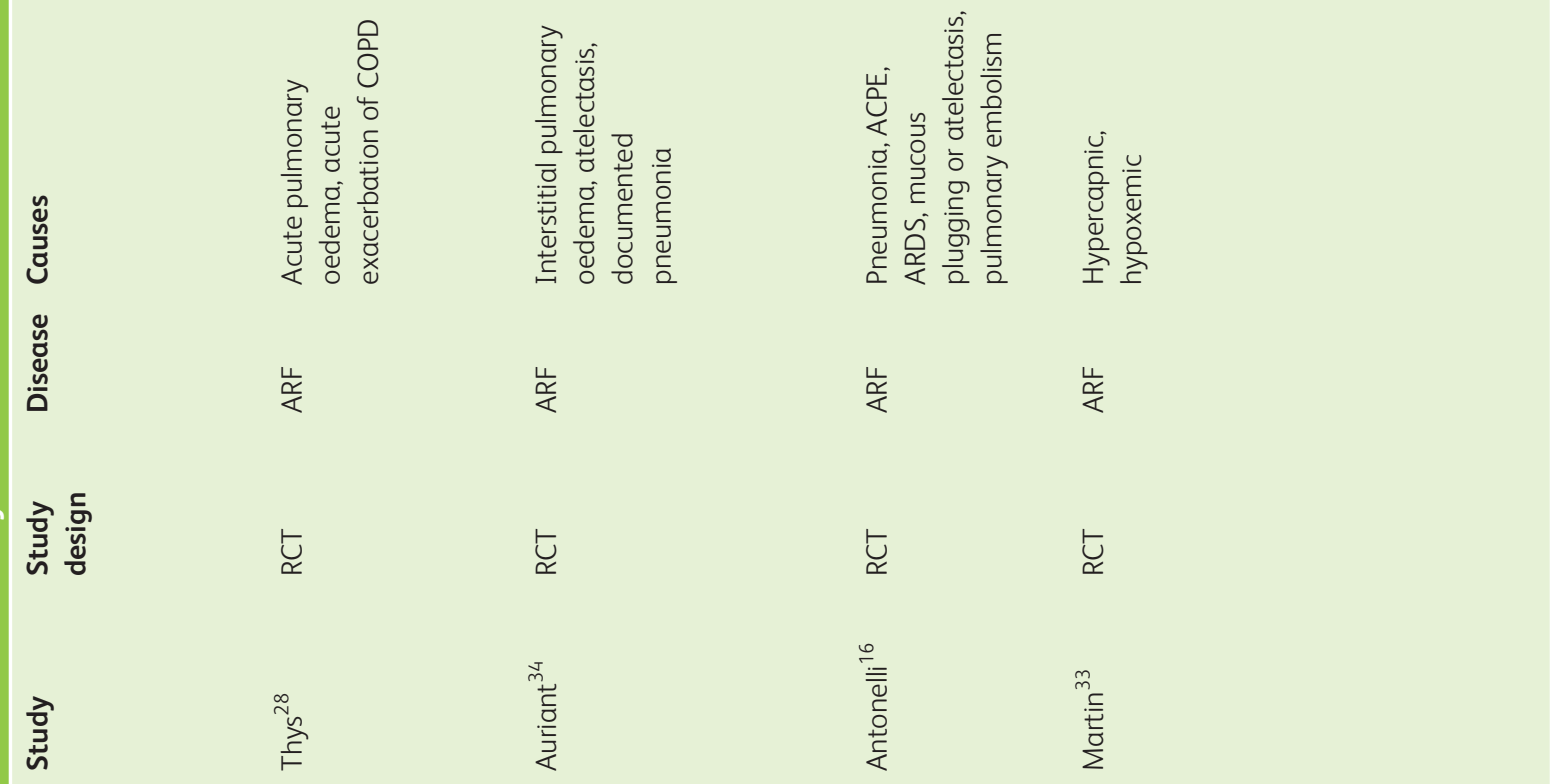

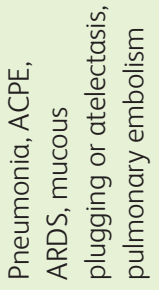

ำ 


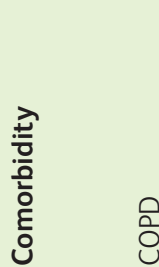

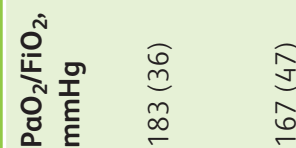

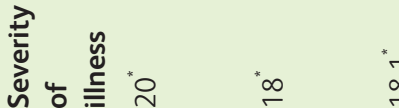

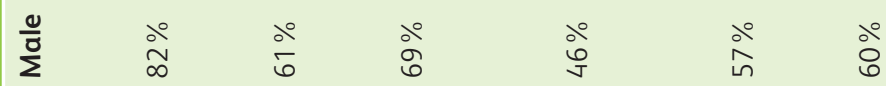

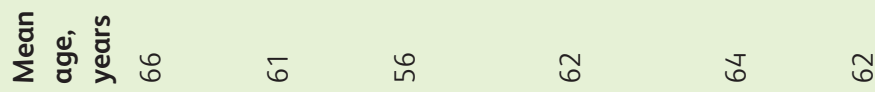

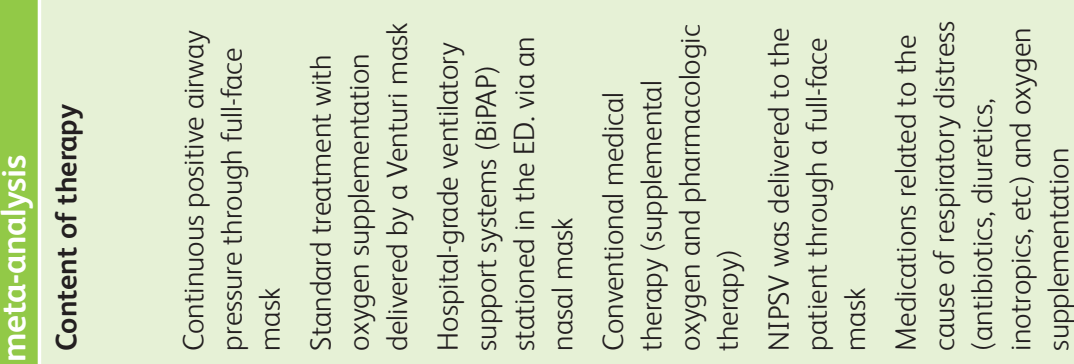

号

$\sum_{\bar{y}}^{2}$

章

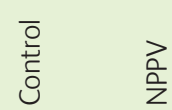

은

商

s

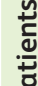

要 $=$
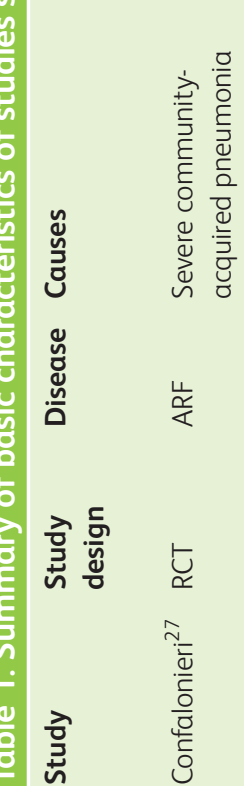

$\stackrel{\infty}{\sim}$

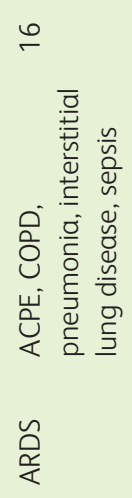

$=$

$\bar{i}$

ॐ

尙崖

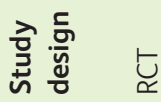

૫

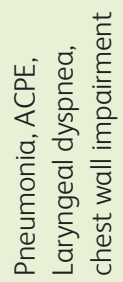

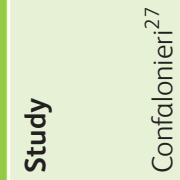

2
จ
3
3

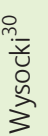

崖

t

i

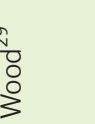




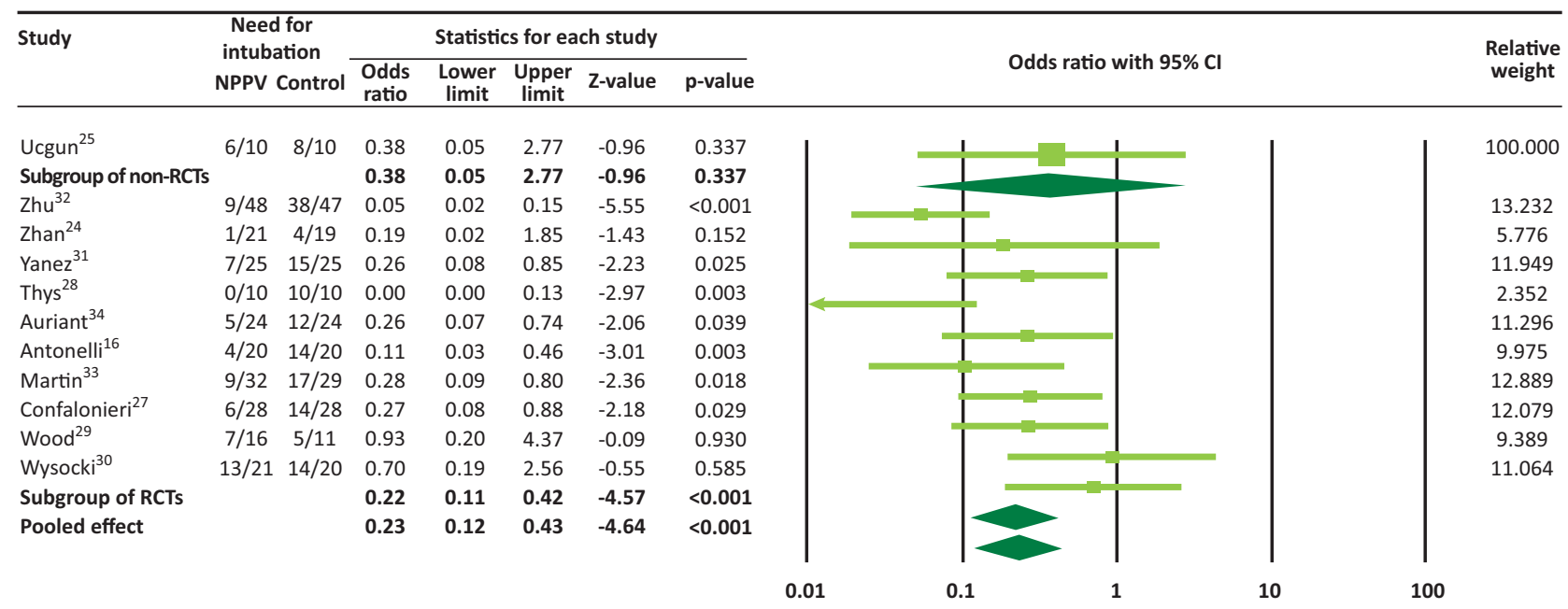

Heterogeneity test

Subgroup of RCTS

$\mathrm{Q}=19.857, \mathrm{df}=9, \mathrm{p}=0.019, \mathrm{I}^{2}=54.68 \%$

Total population

$Q=20.137, d f=10, p=0.028, l^{2}=50.34 \%$

Fig 2. Rate of intubation. NPPV = non-invasive positive-pressure ventilation; RCT = randomised controlled trial.

\section{Quality assessment}

The quality assessment showed that there were low risks of bias and fair application concerns, except for the moderate to high risk of performance and detection bias in RCT studies. Despite unclear or high overall performance and detection bias, most included studies had adequate quality (S3 - Fig S2). Two nonRCT studies had low risk of bias in participants, interventions, missing data and reported results; and the 2009 De Santo et $a l^{26}$ study did not control the confounders (S3 - Fig S2).

\section{Subgroup analysis}

The results of subgroup analysis according to the level of $\mathrm{PaO}_{2} /$ $\mathrm{FiO}_{2}$ at randomisation are presented in Table S2. For a subgroup of patients with $\mathrm{PaO}_{2} / \mathrm{FiO}_{2} \leq 150 \mathrm{mmHg}$, the rate of intubation and hospital mortality were significantly lower in the NPPV group compared with control group (pooled $\mathrm{OR}=0.21(0.05,0.58)$ for rate of intubation, and $0.39(0.17,0.91)$ for hospital mortality). For a subgroup of patients with $150 \mathrm{mmHg}<\mathrm{PaO}_{2} / \mathrm{FiO}_{2} \leq 200 \mathrm{mmHg}$, the rate of intubation was significantly lower in the NPPV group (pooled $\mathrm{OR}=0.27(0.08,0.94)$ ). However, there was no significant difference in the intubation rate, mortality and length of ICU/ hospital stay between the NPPV and control groups in the subgroup of patients with $200 \mathrm{mmHg}<\mathrm{PaO}_{2} / \mathrm{FiO}_{2} \leq 300 \mathrm{mmHg}$ and $\mathrm{PaO}_{2} / \mathrm{FiO}_{2}>300 \mathrm{mmHg}$.

\section{Discussion}

The results of our study highlight that NPPV application is associated with significantly lower intubation rate and in-ICU mortality in patients with ARF. Our results do not support the association between NPPV and in-hospital mortality rate or the length of the ICU and hospital stay. In addition, we showed that NPPV-associated reduction in intubation rate and length of ICU/hospital stay was only apparent for patients with $\mathrm{PaO}_{2} /$
$\mathrm{FiO}_{2}$ levels less than $200 \mathrm{mmHg}$. We did not observe these effects in patients with milder forms of respiratory failure $\left(\mathrm{PaO}_{2} / \mathrm{FiO}_{2}>200 \mathrm{mmHg}\right)$ who received NPPV treatment. Most of the individual studies included in our meta-analysis are RCTs (two prospective two-arm studies were included for better completion), thus our results provide very high level of evidence to support the role of NPPV in managing ARF patients. Our meta-analysis is the most current, with rather broad inclusion parameters. Overall, our results are in agreement with previous studies. A similar meta-analysis was reported by Agarwal et $a l,{ }^{2}$ which assessed the efficacy of NPPV in patients with ALI/ARDS. In this study, the literature search was limited to studies published in 1995-2009. Agarwal et al showed that application of NPPV prevented intubation in 50\% and mortality in $65 \%$ in ALI/ARDS patients. ${ }^{2}$ Additionally, another systematic review reported that the addition of NPPV to standard medical interventions in patients with acute hypoxemic respiratory failure reduces the intubation rate, ICU stay and ICU mortality. ${ }^{9}$ In a 2007 multicentre study of 147 patients with ARDS, NPPV eliminated the need for intubation in $54 \%$ of patients. ${ }^{15} \mathrm{~A}$ Simplified Acute Physiology Score (SAPS II) of more than 34 and the inability to improve $\mathrm{PaO}_{2} / \mathrm{FIO}_{2}$ after 1 hour of NPPV were predictors of failure. ${ }^{15}$ Interestingly, Ucgun et al ${ }^{25}$ also reported that if improvement is not seen in the first day of using NPPV in ARDS patients, invasive mechanical ventilation should be implemented immediately, ${ }^{25}$ suggesting that close monitoring of NPPV effectiveness is necessary for obtaining optimal clinical outcomes. NPPV can be also beneficial to patients with ARF after cardiac surgery. Zhu et al showed that that NPPV can be applied in selected patients with acute respiratory failure after cardiac surgery to reduce the need of re-intubation and improve clinical outcome as compared with conventional treatment. ${ }^{32}$ Pneumonia and a high Acute Physiology and Chronic Health Evaluation II (APACHE II) score of more than 20 might be the independent risk factors of NPPV failure in this group of patients. ${ }^{32}$ 


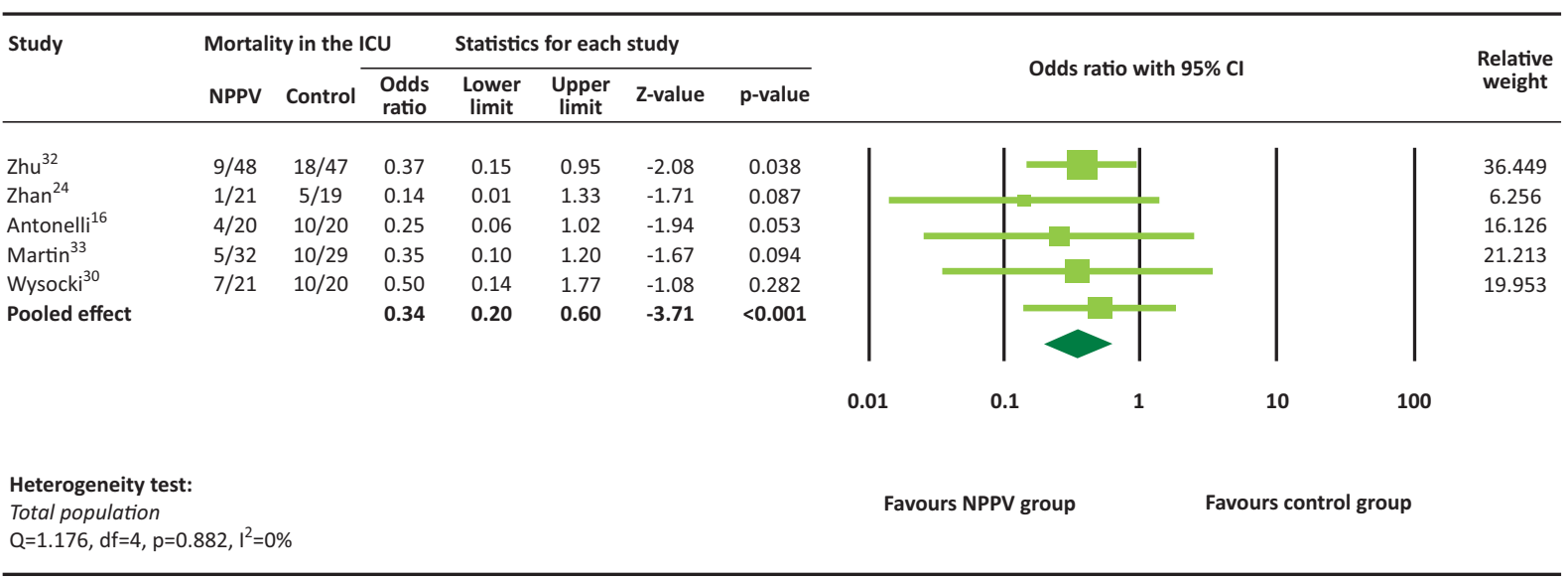

B

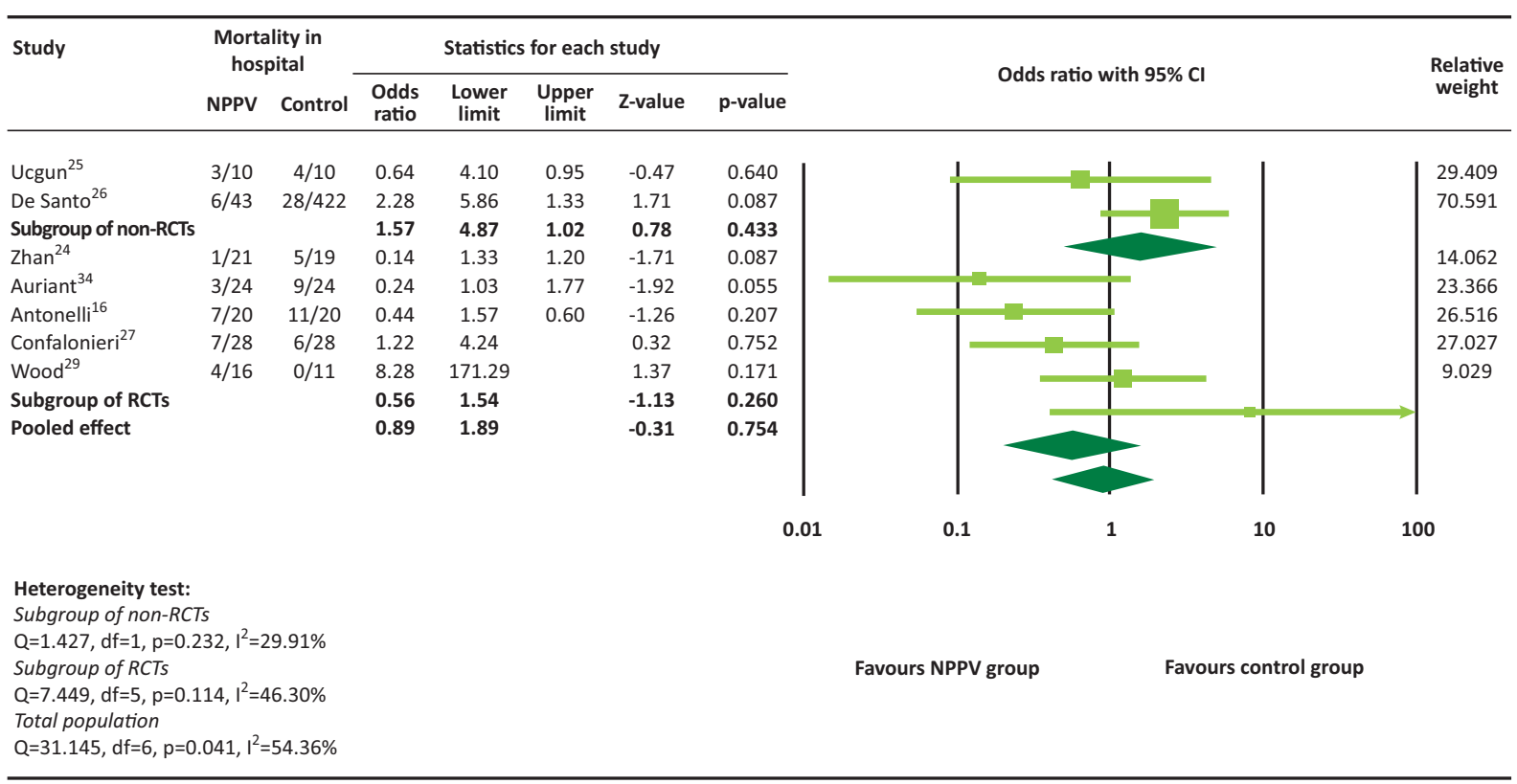

Fig 3. In-ICU (A) and in-hospital (B) mortality rates. NPPV = non-invasive positive-pressure ventilation; $\mathrm{RCT}=$ randomised controlled trial.

Thus, NPPV can be a clinically useful tool in lowering the risk of intubation in patients with ARF. It might be especially valuable for geriatric patients, since intubation is associated with high morbidity and/or mortality in this age group. Further studies or follow-up studies that evaluate the rate of extubation for the same patients that required intubation may provide useful clinical data. Importantly, NPPV is associated with lower in-ICU mortality risk in ARF patients. It must be noted, however, that clinical protocols that identify patients more likely to benefit from NPPV are to be developed. It is also important to identify the patients that are failing NPPV early and proceed to intubation immediately.

\section{Limitations}

The major limitation of the present meta-analysis is the patients' heterogeneity and the design heterogeneity in the included trials. First, in most studies the subject population consisted of older patients, with only three studies focusing on patients younger than 50 years of age..$^{24,25,31}$ Since pulmonary function decreases with age, this patient heterogeneity may skew our results toward over-estimation of the effect of NPPV treatment. All patients in the included studies were at risk of developing ARF and potential intubation, but the underlying courses of their condition and their severity were different. These baseline conditions, undoubtedly, influence the assessment of NPPV effectiveness. There was a large heterogeneity found between studies regarding the use of NPPV and length of hospital stay, suggesting that NPPV might not lead to shorter hospital stay. However, too many confounding events may occur during extended treatments, leading to underestimated association of NPPV with length of hospital stay. Because of literature limitation, our study did not take baseline pulmonary function into account, creating a potential bias towards the severity of certain patients. Additionally, sample sizes of individual studies were small. Moreover, in the De Santo et $a^{26}$ study, the control 
Yu-Jing Liu, Jing Zhao and Hui Tang

A

\begin{tabular}{|c|c|c|c|c|c|c|c|}
\hline \multirow[t]{2}{*}{ Study } & \multicolumn{5}{|c|}{ Statistics for each study } & \multirow[b]{2}{*}{ Difference in means with $95 \% \mathrm{Cl}$} & \multirow{2}{*}{$\begin{array}{c}\text { Relative } \\
\text { weight }\end{array}$} \\
\hline & $\begin{array}{l}\text { Difference } \\
\text { in means }\end{array}$ & $\begin{array}{c}\text { Lower } \\
\text { limit }\end{array}$ & $\begin{array}{l}\text { Upper } \\
\text { limit }\end{array}$ & Z-value & p-value & & \\
\hline Ucgun $^{25}$ & 1.60 & -0.92 & 4.12 & 1.24 & 0.214 & 1 & 49.993 \\
\hline De Santo ${ }^{26}$ & 15.80 & 13.30 & 18.30 & 12.38 & 0.000 & & 50.007 \\
\hline Subgroup of non-RCTs & Is 8.70 & -5.21 & 22.62 & 1.23 & 0.220 & & \\
\hline $\mathrm{Zhu}^{32}$ & -1.32 & -4.07 & 1.43 & -0.94 & 0.347 & 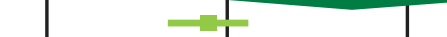 & 16.090 \\
\hline Yanez $^{31}$ & 1.20 & -1.34 & 3.74 & 0.92 & 0.355 & - & 16.714 \\
\hline Thys $^{28}$ & -2.70 & -6.79 & 1.39 & -1.29 & 1.196 & $\longrightarrow$ & 12.256 \\
\hline Auriant ${ }^{34}$ & 2.65 & -7.78 & 13.08 & 0.50 & 0.619 & & 3.616 \\
\hline Antonelli ${ }^{16}$ & -3.00 & -6.42 & 0.42 & -1.72 & 0.086 & $=$ & 14.098 \\
\hline Confalonieri $^{27}$ & -4.20 & -4.92 & -3.48 & -11.51 & 0.000 & $=$ & 21.176 \\
\hline Wood $^{29}$ & 0.90 & -2.72 & 4.52 & 0.49 & 0.626 & & 13.535 \\
\hline Wysocki $^{30}$ & -8.00 & -20.89 & 4.89 & -1.22 & 0.224 & & 2.515 \\
\hline Subgroup of RCTs & -1.64 & -3.81 & 0.54 & -1.48 & 0.140 & & \\
\hline Pooled effectt & -1.39 & -3.54 & 0.76 & -1.27 & 0.204 & & \\
\hline & & & & & -25.00 & -12.50 & \\
\hline
\end{tabular}

Heterogeneity test:

Subgroup of non-RCTS

$Q=61.351, d f=1, p .001, l^{2}=98.37 \%$

Subgroup of RCTS

$Q=26.897, d f=7, p<0.001, l^{2}=73.98 \%$

Total population

$Q=249.480, d f=9, p<0.001, l^{2}=96.39 \%$

B

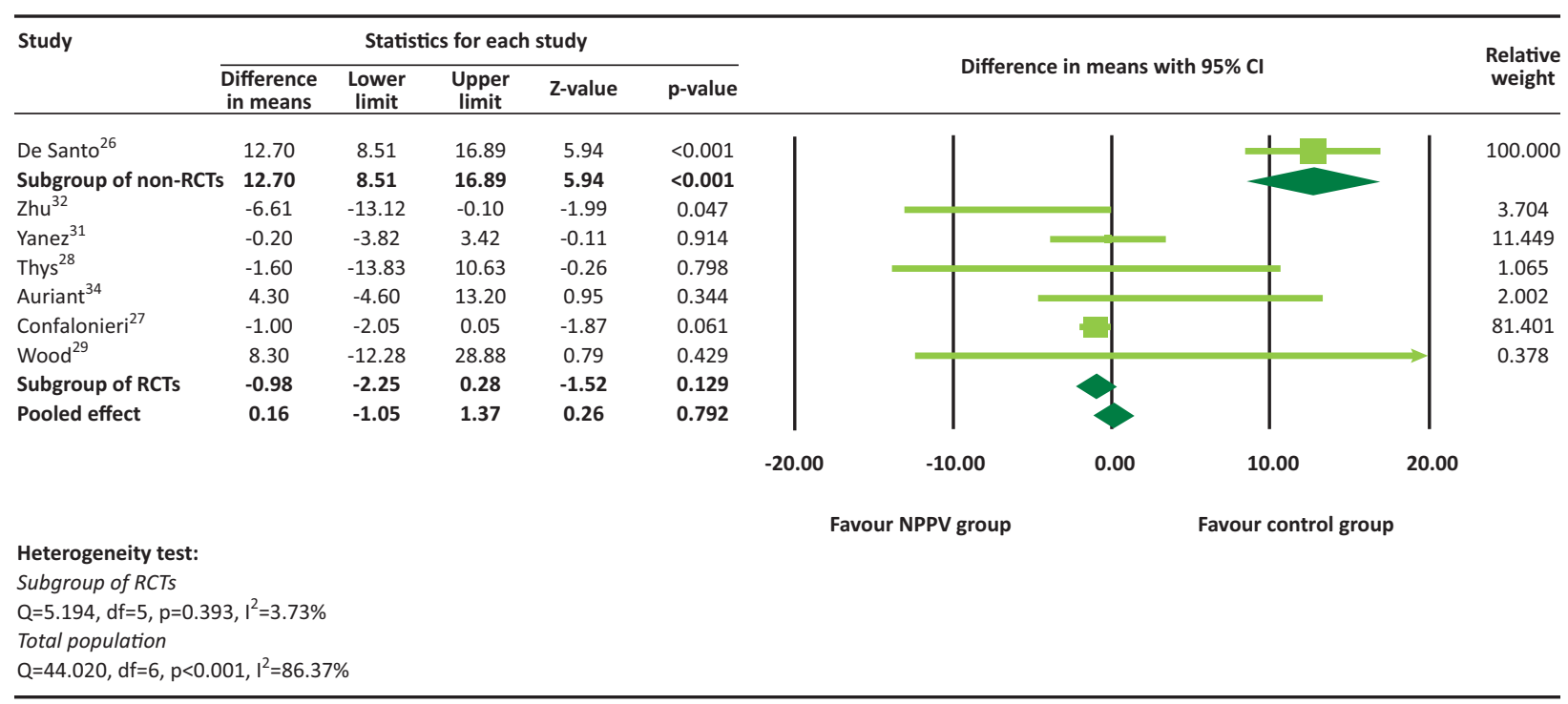

Fig 4. Length of ICU (A) and hospital (B) stay. NPPV = non-invasive positive-pressure ventilation; RCT = randomised controlled trial.

group was almost 10 times larger than the NPPV treatment group. This difference in the effect size could significantly distort our analysis and lead to a high risk of bias. Although the quality assessment of individual studies showed that most of the included studies had adequate quality, performance and detection bias can be difficult to avoid because of ethical issues. Sham-control method was not used in the included studies. However, we feel that this bias did not significantly affect the results of our study since all other parameters were carefully controlled.

Thus, to eliminate the described limitations and develop a standard clinical protocol, further studies (with strict exclusion criteria) that focus on the geriatric population with similar baseline pulmonary function and/or comorbidities are warranted.

\section{Conclusion}

In conclusion, this meta-analysis found that the use of NPPV is associated with lower intubation rate and a lower risk of in-ICU mortality compared with conventional mechanical ventilation and/or non-ventilation therapy. We did not find a significant association between NPPV use and in-hospital mortality or length of ICU/hospital stay. In addition, we showed an NPPV-associated reduction in intubation rate and length of ICU/hospital stay was only apparent for patients with $\mathrm{PaO}_{2} / \mathrm{FiO}_{2}$ levels less than $200 \mathrm{mmHg}$. As additional data become available, further meta-analysis studies with better quality RCTs and more homogenous patient populations are 
warranted. Overall, our observations emphasise that NPPV is a useful alternative for managing patients with ALI/ARDS.

\section{Conflicts of interest}

The authors have no conflicts of interests to declare.

\section{Supplementary material}

Additional supplementary material may be found in the online version of this article at www.clinmed.rcpjournal.org/:

S1 - Supplementary tables

S2 - Fig S1. Analysis of publication bias

S3 - Fig S2. Risk of bias assessment

\section{References}

1 Williams JW Jr, Cox CE, Hargett CW et al. Noninvasive positivepressure ventilation (NPPV) for acute respiratory failure. In: Agency for Healthcare Research and Quality. AHRQ comparative effectiveness reviews. Rockville, MD: AHRQ, 2007.

2 Agarwal R, Aggarwal AN, Gupta D. Role of noninvasive ventilation in acute lung injury/acute respiratory distress syndrome: a proportion meta-analysis. Respir Care 2010;55:1653-60.

3 Thille AW, Contou D, Fragnoli C et al. Non-invasive ventilation for acute hypoxemic respiratory failure: intubation rate and risk factors. Crit Care 2013;17:R269.

4 Zhang H, Slutsky AS. Year in review 2008: Critical Care - respirology. Crit Care 2009;13:225.

5 Nava S, Schreiber A, Domenighetti G. Noninvasive ventilation for patients with acute lung injury or acute respiratory distress syndrome. Respir Care 2011;56:1583-8.

6 Mal S, McLeod S, Iansavichene A, Dukelow A, Lewell M. Effect of out-of-hospital noninvasive positive-pressure support ventilation in adult patients with severe respiratory distress: a systematic review and meta-analysis. Ann Emerg Med 2014;63:600-7.e1.

7 Avdeev SN, Tret'iakov AV, Grigor'iants RA, Kutsenko MA, Chuchalin AG. [Study of the use of noninvasive ventilation of the lungs in acute respiratory insufficiency due exacerbation of chronic obstructive pulmonary disease]. Anesteziol Reanimatol 1998:45-51.

8 Struik FM, Sprooten RT, Kerstjens HA et al. Nocturnal non-invasive ventilation in COPD patients with prolonged hypercapnia after ventilatory support for acute respiratory failure: a randomised, controlled, parallel-group study. Thorax 2014;69:826-34.

9 Keenan SP, Mehta S. Noninvasive ventilation for patients presenting with acute respiratory failure: the randomized controlled trials. Respir Care 2009;54:116-26.

10 Adda M, Coquet I, Darmon M et al. Predictors of noninvasive ventilation failure in patients with hematologic malignancy and acute respiratory failure. Crit Care Med 2008;36:2766-72.

11 Antonelli M, Conti G, Moro ML et al. Predictors of failure of noninvasive positive pressure ventilation in patients with acute hypoxemic respiratory failure: a multi-center study. Intensive Care Med 2001;27:1718-28.

12 Ferrer M, Esquinas A, Leon $\mathrm{M}$ et al. Noninvasive ventilation in severe hypoxemic respiratory failure: a randomized clinical trial. Am J Respir Crit Care Med 2003;168:1438-44.

13 Rana S, Jenad H, Gay PC et al. Failure of non-invasive ventilation in patients with acute lung injury: observational cohort study. Crit Care 2006;10:R79.

14 Lemiale V, Mokart D, Resche-Rigon $\mathrm{M}$ et al. Effect of noninvasive ventilation vs oxygen therapy on mortality among immunocompromised patients with acute respiratory failure: a randomized clinical trial. JAMA 2015;314:1711-9.

15 Antonelli M, Conti G, Esquinas A et al. A multiple-center survey on the use in clinical practice of noninvasive ventilation as a first-line intervention for acute respiratory distress syndrome. Crit Care Med 2007;35:18-25.
16 Antonelli M, Conti G, Bufi M et al. Noninvasive ventilation for treatment of acute respiratory failure in patients undergoing solid organ transplantation: a randomized trial. JAMA 2000;283:235-41.

17 Lemiale V, Resche-Rigon M, Azoulay E. Early non-invasive ventilation for acute respiratory failure in immunocompromised patients (IVNIctus): study protocol for a multicenter randomized controlled trial. Trials 2014;15:372.

18 Rocker GM, Mackenzie MG, Williams B, Logan PM. Noninvasive positive pressure ventilation: successful outcome in patients with acute lung injury/ARDS. Chest 1999;115:173-7.

19 Liberati A, Altman DG, Tetzlaff J et al. The PRISMA statement for reporting systematic reviews and meta-analyses of studies that evaluate health care interventions: explanation and elaboration. J Clin Epidemiol 2009;62:e1-34.

20 Higgins JPT, Green S (eds). Cochrane handbook for systematic reviews of interventions, version 5.1.0. The Cochrane Collaboration, 2011

21 Sterne JAC, Higgins JPT, Reeves BC on behalf of the development group for ACROBAT-NRSI. A Cochrane Risk Of Bias Assessment Tool: for Non-Randomized Studies of Interventions (ACROBATNRSI), version 1.0.0. The Cochrane Collaboration, 2014.

22 Takkouche B, Cadarso-Suarez C, Spiegelman D. Evaluation of old and new tests of heterogeneity in epidemiologic meta-analysis. Am J Epidemiol 1999;150:206-15.

23 National Research Council. Combining information: statistical issues and opportunities for research. Washington, DC: National Academy Press, 1992.

24 Zhan Q, Sun B, Liang L et al. Early use of noninvasive positive pressure ventilation for acute lung injury: a multicenter randomized controlled trial. Crit Care Med 2012;40:455-60.

25 Ucgun I, Yildirim H, Metintas M, Guntulu AK. The efficacy of noninvasive positive pressure ventilation in ARDS: a controlled cohort study. Tuberk Toraks 2010;58:16-24.

26 De Santo LS, Bancone C, Santarpino G et al. Noninvasive positivepressure ventilation for extubation failure after cardiac surgery: pilot safety evaluation. J Thorac Cardiovasc Surg 2009;137:342-6.

27 Confalonieri M, Potena A, Carbone G et al. Acute respiratory failure in patients with severe community-acquired pneumonia. A prospective randomized evaluation of noninvasive ventilation. Am J Respir Crit Care Med 1999;160:1585-91.

28 Thys F, Roeseler J, Reynaert M, Liistro G, Rodenstein DO. Noninvasive ventilation for acute respiratory failure: a prospective randomised placebo-controlled trial. Eur Respir J 2002;20:545-55.

29 Wood KA, Lewis L, Von Harz B, Kollef MH. The use of noninvasive positive pressure ventilation in the emergency department: results of a randomized clinical trial. Chest 1998;113:1339-1346.

30 Wysocki M, Tric L, Wolff MA, Millet H, Herman B. Noninvasive pressure support ventilation in patients with acute respiratory failure. A randomized comparison with conventional therapy. Chest 1995;107:761-8.

31 Yanez LJ, Yunge M, Emilfork $\mathrm{M}$ et al. A prospective, randomized, controlled trial of noninvasive ventilation in pediatric acute respiratory failure. Pediatr Crit Care Med 2008;9:484-9.

32 Zhu GF, Wang DJ, Liu S, Jia M, Jia SJ. Efficacy and safety of noninvasive positive pressure ventilation in the treatment of acute respiratory failure after cardiac surgery. Chin Med J (Engl) 2013;126:4463-9.

33 Martin TJ, Hovis JD, Costantino JP et al. A randomized, prospective evaluation of noninvasive ventilation for acute respiratory failure. Am J Respir Crit Care Med 2000;161:807-13.

34 Auriant I, Jallot A, Hervé P et al. Noninvasive ventilation reduces mortality in acute respiratory failure following lung resection. Am J Respir Crit Care Med 2001;164:1231-5.

Address for correspondence: Dr Jing Zhao, Department of Thoracic Surgery, The Military General Hospital of Beijing PLA, No 5 Nanmencang, Dongcheng District, Beijing 100700, China. Email: 13910224230@139.com 